\title{
Corrida em ambiente quente altera o perfil leucocitário de sujeitos treinados saudáveis
}

\author{
Race in a hot environment changes the leukocyte profile in healthy trained subjects
}

\author{
Antonio Carlos Silva-Filho ${ }^{1} \bowtie$, Carlos José Dias ${ }^{1}$, Herikson Araújo Costaㄹ, Cristiano Teixeira Mostarda ${ }^{1}$, \\ Francisco Navarro', Mário N. Sevilio de Oliveira Jr. ${ }^{1}$
}

${ }^{1}$ Departamento de Educação Física da Universidade Federal do Maranhão. São Luís, MA.

\section{RESUMO}

Objetivos: Analisar os efeitos de uma corrida de $15 \mathrm{~km}$ ao ar livre em ambiente de alta temperatura na modulação da leucocitose em homens saudáveis treinados em corrida.

Métodos: A amostra foi composta por 14 homens que participavam de um grupo de corrida recreativo. Foram incluídos voluntários que declarassem ser capazes de percorrer a distância mínima de $15 \mathrm{~km}$, não estivessem tomando nenhum medicamento imunossupressor e não tivessem nenhuma doença infecciosa. Os critérios de exclusão foram hipertensão arterial em repouso antes da corrida, histórico de doenças osteomioarticulares, metabólicas e/ou cardiovasculares, e não completar o percurso da corrida. Amostras de sangue venoso antes e após a corrida foram coletadas para determinação do hematócrito e contagem de células imunes por imunocitoquímica.

Resultados: Observou-se aumento no número de leucócitos totais e neutrófilos no momento pós corrida $\left(9,31 \pm 2,4 \times 10^{3}\right.$ células $/ \mu \mathrm{L}$ e $7,64 \pm 3,4 \times 10^{3}$ células/ $\mu \mathrm{L}$ respectivamente) em comparação ao momento pré corrida $\left(5,52 \pm 0.2 \times 10^{3}\right.$ células $/ \mu \mathrm{L}$ e $2,90 \pm 0,6 \times 10^{3}$ células $/ \mu \mathrm{L}$ respectivamente) $(\mathrm{p}<0,05)$. Houve diminuição no número de linfócitos e eosinófilos no momento pós corrida $\left(1,34 \pm 0,3 \times 10^{3}\right.$ e $0,36 \pm 0,2 \times 10^{3}$ células $/ \mu \mathrm{L}$ respectivamente) comparado ao pré corrida $\left(1,67 \pm 0,3 \times 10^{3}\right.$ e $0,22 \pm 0,1 \times 10^{3}$ células $/ \mu \mathrm{L}$ respectivamente $)(\mathrm{p}<0,05)$. Não foram observadas diferenças significativas no número de monócitos e basófilos no momento pós corrida $\left(0,45 \pm 0,1 \times 10^{3}\right.$ e $0,9 \pm 0,3 \times 10^{3}$ células/ $\mu \mathrm{L}$ respectivamente) comparado ao pré corrida $\left(0,40 \pm 0,08 \times 10^{3}\right.$ e $0,8 \pm 0,3 \times 10^{3}$ células $/ \mu \mathrm{L}$ respectivamente) $(\mathrm{p}>0,05)$.

Conclusões: A corrida de $15 \mathrm{~km}$ ao ar livre, em ambiente de alta temperatura, induziu a uma cinética leucocitária típica, com leucocitose às custas do aumento no número de neutrófilos, assim como queda no número de linfócitos e eosinófilos, em homens saudáveis com prévio treinamento em corrida. Estes resultados ajudam a compreender melhor a leucocitose induzida pelo exercício e podem indicar a intensidade do estresse promovido pelo exercício em condições ambientais extremas.

DESCRITORES: leucocitose; termoregulação; corrida.

\section{ABSTRACT}

Aims: To assess the effects of an outdoor race of $15 \mathrm{~km}$ in a hot environment on leukocyte kinetics in healthy trained men.

Methods: The sample consisted of 14 men who participated in a recreational race group. Volunteers who said they were able to run a minimum distance of $15 \mathrm{~km}$, were not taking any immunosuppressants, and had no infectious disease were included in the study. The exclusion criteria were the following: hypertension at rest before the race, history of musculoskeletal, metabolic and/or cardiovascular diseases, and failure to finish the race. Venous blood samples were collected before and after the race for determination of hematocrit levels and immune cell count by immunocytochemistry.

Results: An increase in total leukocyte and neutrophil count was observed after the race $\left(9.31 \pm 2.4 \times 10^{3}\right.$ cells $/ \mu \mathrm{L}$ and $7.64 \pm 3.4 \times 10^{3}$ cells $/ \mu \mathrm{L}$, respectively) compared to the pre-race period $\left(5.52 \pm 0.2 \times 10^{3}\right.$ cells $/ \mu \mathrm{L}$ and $2.90 \pm 0.6 \times 10^{3}$ cells $/ \mu \mathrm{L}$, respectively), $(\mathrm{p}<0.05)$. There was a decrease in lymphocyte and eosinophil count after the race $\left(1.34 \pm 0.3 \times 10^{3}\right.$ and $0.36 \pm 0.2 \times 10^{3}$ cells $/ \mu \mathrm{L}$, respectively) compared to the pre-race period $\left(1.67 \pm 0.3 \times 10^{3}\right.$ and $0.22 \pm 0.1 \times 10^{3}$ cells $/ \mu \mathrm{L}$, respectively) $(\mathrm{p}<0.05)$. There was no statistically significant difference in monocyte and basophil count after the race $\left(0.45 \pm 0.1 \times 10^{3}\right.$ and $0.9 \pm 0.3 \times 10^{3}$ cells $/ \mu \mathrm{L}$, respectively) compared to the pre-race period $\left(0.40 \pm 0.08 \times 10^{3}\right.$ and $0.8 \pm 0.3 \times 10^{3}$ cells $/ \mu \mathrm{L}$, respectively) $(\mathrm{p}>0.05)$

Conclusions: The 15-km outdoor race in a hot environment led to a typical leukocyte kinetics, resulting in leukocytosis owing to the increase in neutrophil count as well as to a decrease in lymphocyte and eosinophil count in healthy trained men. These findings shed some further light upon exercise-induced leukocytosis and may indicate the level of stress produced by exercise under extreme environmental conditions.

KEY WORDS: leukocytosis; body temperature regulation; running.

Recebido: novembro, 2015

Aceito: março, 2016

Este artigo está licenciado sob forma de uma licença Creative Common Atribuição 4.0 Internacional, que permite uso irrestrito, distribuição e reprodução em qualquer meio, descle que a publicação original seja corretamente citâa. 
Abreviaturas: NF, neutrófilos; LF, linfócitos; EOS, eosinófilos; BAS, basófilos; MC, monócitos; NK, natural killer; IMC, índice de massa corporal; $\mathrm{VO}_{2} \max$, consumo máximo de oxigênio.

\section{INTRODUÇÃO}

Sabe-se que uma sessão de exercício induz ao aumento na quantidade de células imunes circulantes, fenômeno denominado de leucocitose induzida pelo exercício. A leucocitose induzida pelo exercício pode ser caracterizada pelo aumento da concentração sanguínea principalmente de neutrófilos (NF), linfócitos (LF) T e B, e células Natural Killer (NK) [1].

Os NF compõem entre 40-70\% dos leucócitos circulantes [2], e são os principais contribuintes para a leucocitose induzida pelo exercício [3]. Os LF têm a função de gerenciamento da imunidade adquirida, e compõem entre $20-50 \%$ das células imunes circulantes [2]. Demonstram sua concentração aumentada durante o exercício, e, imediatamente após o exercício, reduzem-se novamente, retornando aos valores basais em até 24 horas [4]. Os basófilos (BAS) e os eosinófilos (EOS), denominados granulócitos, perfazem 1 a $6 \%$ das células imunes circulantes [2] e possuem papel importante na resposta inflamatória, pois liberam substâncias que dilatam os vasos e iniciam a cascata do ácido araquidônico [5].

Estudos prévios demonstram que uma sessão aguda de exercício de alta intensidade em elevada temperatura ambiental induz a um aumento maior no número de leucócitos totais, NF, LF, células NK e na produção de citocinas, quando comparada com uma sessão de exercício em ambiente com temperatura menor que $28^{\circ} \mathrm{C}[6,7]$. Essa responsividade pode ser associada ao fato de que as células possuem receptores sensíveis à adrenalina e ao cortisol, hormônios em elevadas concentrações no exercício de alta intensidade [3]. Os LF CD4+ e CD8+ possuem a menor densidade de receptores $\beta$-adrenérgicos $[3,8]$. Em contrapartida, o cortisol também tem influência sobre as células imunes, diminuindo a concentração de monócitos (MC), EOS, LF CD4+ e CD8+ e aumentando a concentração dos $\mathrm{NF}[3,8]$. Além disso, elevadas temperaturas estimulam o aumento da atividade simpática e a redução da atividade parassimpática, que podem ser precursores da resposta neuroendócrina ao frente ao exercício físico [9].

O exercício físico em altas temperaturas pode afetar a ação das enzimas glicolíticas e aumentar a osmolaridade sanguínea e intersticial, favorecendo a diminuição do desempenho, o que em uma condição de competição, pode resultar na diminuição da velocidade média e aumento do tempo de prova $[10,11]$. Esse estresse causado pelo exercício é sinalizado por hormônios, que também afetam as células imunes, diminuindo sua adesão às paredes dos vasos [12]. No entanto, as sessões de exercícios citadas foram realizadas em ambiente laboratorial com a temperatura controlada, não mimetizando a prática diária de uma sessão de exercício. Portanto, é importante que sejam feitos estudos que investiguem a leucocitose induzida pelo exercício físico em um ambiente real, de temperatura quente.

Dessa forma, o objetivo deste estudo foi analisar os efeitos da corrida ao ar livre em ambiente de alta temperatura na modulação da leucocitose por meio da contagem sanguínea dos NF, LF, MC, BAS e EOS. Hipotetizamos que a corrida ao ar livre em ambiente de alta temperatura induzirá à leucocitose, especialmente dos NF, e causará uma queda dos LF e EOS.

\section{MÉTODOS}

Foram selecionados para o estudo sujeitos saudáveis, do sexo masculino, treinados em corrida. Os participantes faziam parte de um grupo de corrida recreativo que se encontrava três vezes por semana, correndo entre 10 a $21 \mathrm{~km}$ por treino. Foram incluídos voluntários que declarassem serem atletas capazes de percorrer a distância mínima de $15 \mathrm{~km}$, não estivessem tomando nenhum medicamento imunossupressor e não tivessem nenhuma doença infecciosa. Os critérios de exclusão foram: a) antes da corrida, pressão arterial de repouso $\geq 130 \mathrm{mmHg}$ sistólica ou $\geq 80 \mathrm{mmHg}$ diastólica em decúbito dorsal; b) histórico de doenças osteomioarticulares, metabólicas e/ou cardiovasculares; c) não completar o percurso da corrida. Todos os sujeitos foram informados sobre os procedimentos experimentais e assinaram o Termo de Consentimento Livre Esclarecido de participação no estudo. Todos os procedimentos foram aprovados pelo Comitê de Ética em Pesquisa Institucional sob o número 545.550/2014 e realizados segundo as recomendações da resolução 466/12 do Conselho Nacional de Saúde.

Os sujeitos compareceram ao laboratório em dois momentos. Na primeira visita, foram realizadas as avaliações antropométricas, de composição corporal e da capacidade cardiorrespiratória. Após 14 dias compareceram para a corrida e as avaliações antes e logo depois da mesma (Figura 1). 


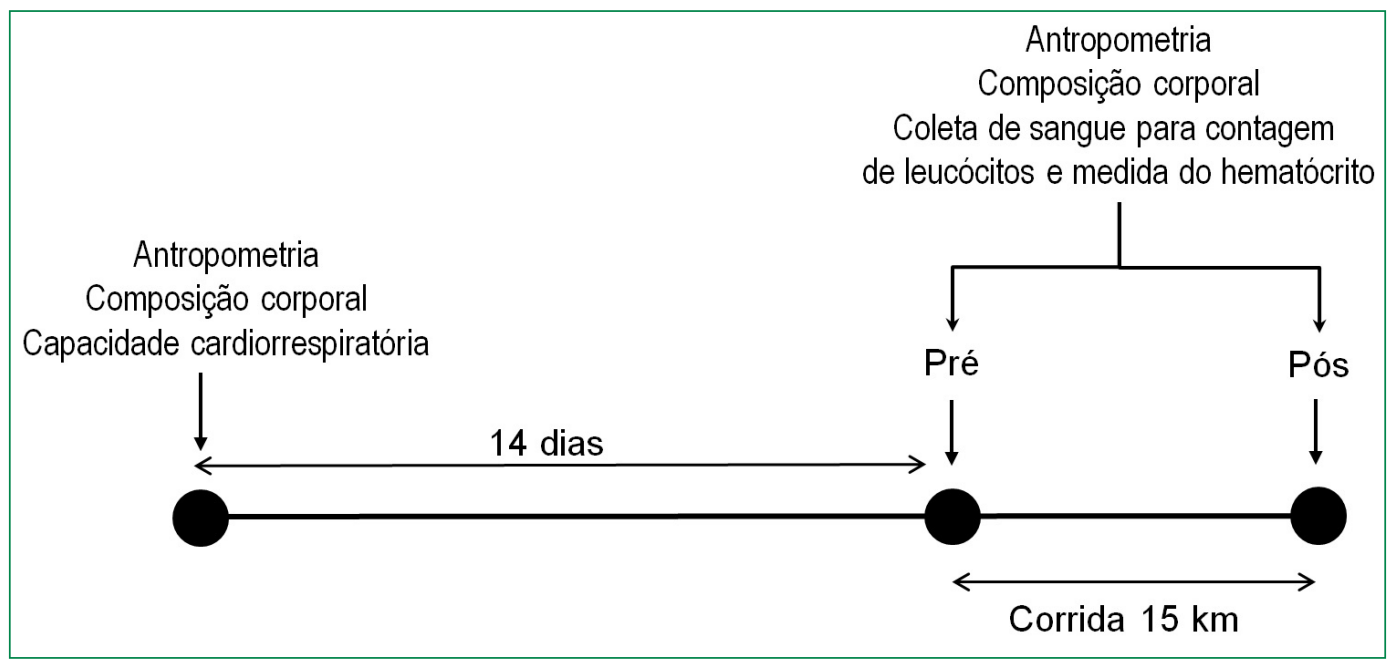

Figura 1. Desenho experimental do estudo.

O peso e a estatura dos sujeitos, despidos de qualquer vestimenta ou acessório, foram medidos por meio da balança com estadiômetro (Welmy ${ }^{\circledR}$ W300, Santa Bárbara do Oeste, Brasil) com precisão de $0,5 \mathrm{~cm}$ para estatura e $0,05 \mathrm{~kg}$ para o peso. A composição corporal foi medida por bioimpedância tetra polar (Biodynamics ${ }^{\circledR}$, BIA450, Washington, EUA) respeitando os procedimentos recomendados pelo fabricante para análise do índice de massa corporal (IMC) e da taxa metabólica basal.

A capacidade cardiorrespiratória, avaliada pelo consumo máximo de oxigênio $\left(\mathrm{VO}_{2} \mathrm{max}\right)$, foi medida por meio da ergoespirometria, realizada duas semanas antes da corrida. O protocolo utilizou velocidade progressiva, com fase inicial de adaptação à velocidade de $4,0 \mathrm{~km} / \mathrm{h}$ e inclinação de $1 \%$. O teste foi iniciado com velocidade constante de $5,0 \mathrm{~km} / \mathrm{h}$, com incremento de $1,0 \mathrm{~km} / \mathrm{h}$ a cada minuto e a manutenção da inclinação a $1 \%$. O equipamento é composto pelo analisador de gases $\left(\mathrm{VO}_{2000}\right.$, MedGraphics ${ }^{\circledR}$, Saint Paul, Minnesota, EUA) conectado ao computador calibrado antes do início de cada teste a uma esteira ergométrica (Inbramed $^{\circledR}$, Master Super ATL).

Após 14 dias, os sujeitos retornaram ao laboratório no dia da corrida, permaneceram em repouso para a coleta da amostra sanguínea venosa antecubital (momento pré). Imediatamente após a corrida, foi coletada outra amostra sanguínea venosa (momento pós). Para a coleta de sangue, os sujeitos permaneceram em decúbito dorsal, sendo coletados $18 \mathrm{ml}$ de sangue da veia antecubital. As amostras foram armazenadas em tubos com anticoagulante, refrigeradas e enviadas ao laboratório para as análises das populações de leucócitos totais, LF, NF, MC, EOS, BAS e determinação do hematócrito, imediatamente após o término da ultima coleta.

A contagem dos leucócitos foi feita por meio da técnica padronizada de imunocitoquímica [13] (Advia 2120, Hematology System, Siemens ${ }^{\circledR}$ Healthcare Diagnostics, Forchheim, Germany) realizada no Centro de Pesquisa Clínica do Hospital Universitário da Universidade Federal do Maranhão (CEPEC - HUUFMA).

A temperatura ambiente e a umidade relativa do ar no momento da corrida foram medidas a cada cinco minutos, utilizando termohigrômetro digital (Instrutherm $^{\circledR}$, HT-260, São Paulo, Brasil) até a passagem do último atleta.

A corrida foi realizada na cidade de São Luís, Maranhão, Brasil, com altitude 4 metros acima do nível do mar. O percurso utilizado para realizar a corrida possuía $3 \mathrm{~km}$ em uma avenida com extensão de 1500 metros de ida e 1500 metros de volta, plana e asfaltada, onde os atletas percorreram por cinco vezes o percurso até totalizar $15 \mathrm{~km}$. O percurso possuía pontos de hidratação a cada $1,5 \mathrm{~km}$, onde os atletas hidratavam-se ad libitum. A corrida iniciou-se às 11:00 horas da manhã e o último atleta finalizou a corrida às 12:50 horas da tarde.

Os resultados foram apresentados como média e desvio padrão. Foram utilizados os testes de Grubbs para determinar a existência de valores discrepantes e o teste de D'Agostino e Pearson para determinar a normalidade dos dados (sendo homoscedásticos), $t$ de Student, considerando estatisticamente significante o $p \leq 0,05$. Os dados foram analisados pelo software GraphPad $^{\circledR}$ Prism 5. 


\section{RESULTADOS}

A amostra foi composta por 14 sujeitos que atenderam aos critérios de inclusão. A média de idade dos participantes foi de $41 \pm 10$ anos e a média do $\mathrm{VO}_{2}$ max foi de $54 \pm 12,14 \mathrm{ml} \cdot \mathrm{kg}^{-1} \cdot \mathrm{min}^{-1}$. Características antropométricas e outros dados de antes e após a corrida são mostrados na Tabela 1. A temperatura durante a corrida foi de $38,75 \pm 1,75^{\circ} \mathrm{C}$ e a umidade relativa de $37,37 \pm 4,65 \%$.

Quando comparado o momento pré corrida com o momento pós corrida, observou-se redução significativa do peso e do IMC e aumento significativo do hematócrito. Não se observou diferença significativa nos valores de taxa metabólica basal (Tabela 1).

Ao avaliar a contagem de células imunes nos dois momentos (antes e após a corrida), observou-se aumento significativo no número de leucócitos totais e NF no momento pós-corrida comparado ao momento pré-corrida (Tabela 2 e Figura 2). Esse aumento correspondente a $40,71 \%$ para leucócitos totais e $62,03 \%$ para NF (Figura 3). Em contrapartida, observou-se redução significativa no número de LF e EOS no momento póscorrida comparado ao momento pré-corrida (Tabela 2 e Figura 2). Essa redução correspondente a $24,52 \%$ para os linfócitos e 62,98\% para os eosinófilos (Figura 3).
Tabela 1. Variáveis de caracterização dos 14 voluntários homens, saudáveis e treinados, submetidos a uma corrida de $15 \mathrm{~km}$ ao ar livre em ambiente de alta temperatura, nos momentos pré e pós-corrida.

Tabela 2. Contagem de células imunes em 14 voluntários homens, saudáveis e treinados, submetidos a uma corrida de

$15 \mathrm{~km}$ ao ar livre em ambiente de alta temperatura, nos momentos pré e pós-corrida.

\begin{tabular}{lccc}
\hline \multicolumn{1}{c}{ Variáveis } & $\begin{array}{c}\text { Pré-corrida } \\
\text { Média } \pm \text { desvio padrão }\end{array}$ & $\begin{array}{c}\text { Pós-corrida } \\
\text { Média } \pm \text { desvio padrão }\end{array}$ & p* \\
\hline Estatura $(\mathrm{m})$ & $168,13 \pm 7,07$ & - & - \\
\hline Peso $(\mathrm{kg})$ & $63,92 \pm 7,5$ & $61,69 \pm 7,2$ & $<0,0001$ \\
Índice de massa corporal $\left(\mathrm{kg} / \mathrm{m}^{2}\right)$ & $22,56 \pm 1,8$ & $21,77 \pm 1,7$ & $<0,0001$ \\
Hematócrito $(\%)$ & $43,16 \pm 3,0$ & $46,68 \pm 3,2$ & 0,0008 \\
\hline Taxa metabólica basal (calorias) & $1652 \pm 209$ & $1652 \pm 204$ & 0,9700 \\
\hline
\end{tabular}

* Teste t de Student.

\begin{tabular}{lccc}
\hline \multicolumn{1}{c}{ Tipos de células } & $\begin{array}{c}\text { Pré-corrida } \\
\text { Média } \pm \text { desvio padrão* }\end{array}$ & $\begin{array}{c}\text { Pós-corrida } \\
\text { Média } \pm \text { desvio padrão* }\end{array}$ & p† \\
\hline Leucócitos totais & $5,52 \pm 0,2$ & $9,31 \pm 2,4$ & $<0,0001$ \\
Neutrófilos & $2,90 \pm 0,6$ & $7,64 \pm 3,4$ & 0,0003 \\
Linfócitos & $1,67 \pm 0,3$ & $1,34 \pm 0,3$ & 0,0338 \\
Monócitos & $0,40 \pm 0,08$ & $0,45 \pm 0,1$ & 0,1003 \\
Eosinófilos & $0,36 \pm 0,2$ & $0,22 \pm 0,1$ & 0,0363 \\
Basófilos & $0,8 \pm 0,03$ & $0,9 \pm 0,03$ & 0,4067 \\
\hline
\end{tabular}

* Número $\times 10^{3} \mathrm{cel} / \mu \mathrm{L}$. + Teste t de Student.

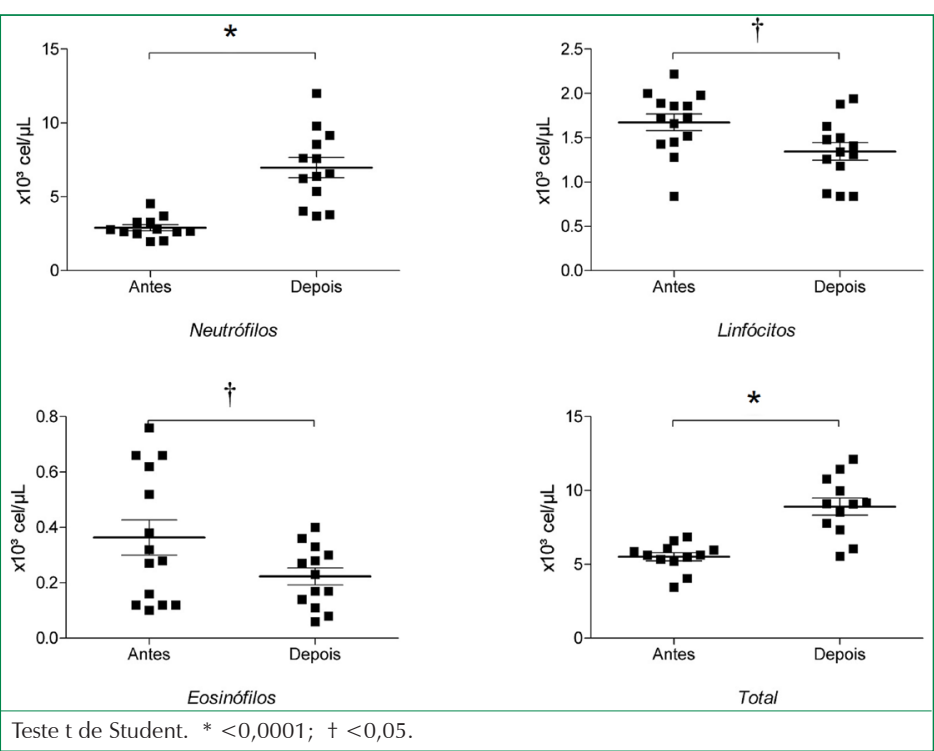

Figura 2. Contagem das células imunes antes e depois de uma corrida de $15 \mathrm{~km}$ ao ar livre em ambiente de alta temperatura, em 14 homens saudáveis e treinados. Os valores são apresentados como média e desvio padrão.

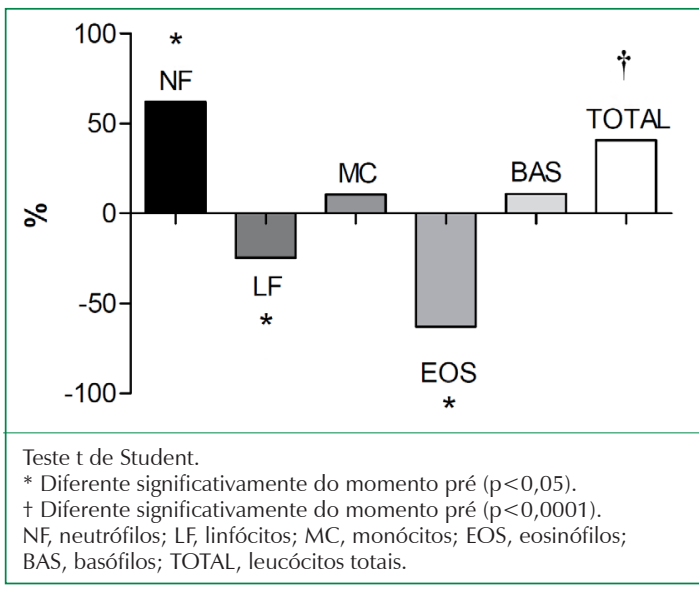

Figura 3. Alteração percentual (\%) das células imunes no momento pós em relação ao momento pré de uma corrida de $15 \mathrm{~km}$ em ambiente de alta temperatura, em 14 homens saudáveis e treinados. 
Não foram observadas alterações significativas no número de $\mathrm{MC}$ e BAS no momento pós-corrida comparado com o momento pré-corrida (Tabela 2).

\section{DISCUSSÃO}

O objetivo deste estudo foi analisar os efeitos de uma corrida ao ar livre em ambiente de alta temperatura e umidade relativa baixa do ar na contagem de leucócitos totais, NF, MC, LF, EOS e BAS de sujeitos treinados. A hipótese inicial foi confirmada, uma vez que se observou a leucocitose após a corrida nessas condições ambientais. Observou-se que a leucocitose foi modulada positivamente pelo aumento na contagem de NF. Em contrapartida, observaram-se reduções na contagem dos LF, EOS e nenhuma alteração para MC e BAS.

O Colégio Americano de Medicina do Esporte considera um ambiente quente quando a temperatura está acima de $27^{\circ} \mathrm{C}$ e a umidade relativa do ar abaixo de $40 \%$. O ambiente quente pode ser impróprio para prática de exercício, pois favorece o desenvolvimento de complicações como a hipertermia e a desidratação, que afetam o desempenho [14].

Os sujeitos da presente amostra demonstraram uma redução significativa de massa corporal. Essa condição é explicada pela desidratação, sendo confirmada pela alteração na relação soluto/solvente [15], demonstrada na concentração do hematócrito, que foi significativamente maior após a corrida no presente estudo.

Em relação às células imunes, observou-se leucocitose, às custas do aumento dos NF circulantes, como já demonstrado em estudos prévios $[16,17]$. Esse aumento pode ser parcialmente explicado pelo direcionamento dos NF para o local de uma possível lesão, sendo atraídos por quimiocinas [3]. As catecolaminas também são determinantes para a leucocitose, por elevarem o volume de ejeção cardíaco, causando o estresse de cisalhamento e o consequente desprendimento dos leucócitos das paredes dos vasos, direcionando-os para a corrente sanguínea e diminuindo a expressão de moléculas de adesão, como a L-selectina $[12,18]$. Estudos demonstram também que o aumento no número de NF está relacionado com o aumento da concentração de cortisol, o que pode ser um fator de manutenção da neutrofilia após o exercício [3]. A noradrenalina também pode mobilizar células imunes de órgãos linfoides, através da estimulação $\beta$-adrenérgica $[19,20]$.

Estudos demonstram que a prática de exercício físico em ambientes com temperaturas elevadas pode estimular uma leucocitose mais acentuada do que em condições ambientais normais [6,7]. Isso pode ser parcialmente explicado pelo maior aumento da atividade simpática e dos níveis de catecolaminas durante o exercício físico em ambientes com temperaturas elevadas $[9,21]$.

Ainda existem dúvidas sobre qual fator é realmente importante na leucocitose induzida pelo exercício em relação à atividade simpática; se é disparada pelo aumento da temperatura corporal por si só, pela ativação neuroimunoendócrina, ou por um conjunto de fatores [21]. Mas o que de fato se sabe é que o exercício em altas temperaturas causa um aumento significativo na quantidade de adrenalina circulante quando se compara com o mesmo exercício em temperatura neutra ou fria, causando assim maior ativação dos receptores $\beta$-adrenérgicos [6]. A alta temperatura combinada com o exercício também aumenta as concentrações de cortisol acima dos valores do exercício em ambiente neutro [6]. Com característica imunossupressora importante, o cortisol sinaliza o desconforto e o estresse causado pela alta temperatura interna sobre o eixo hipotálamo-hipófise-adrenal [22]. Essa alta concentração de cortisol pode ser um fator disparador da apoptose dos LF e EOS, causando diminuição de suas presenças na circulação [23]. Os dados do presente estudo demonstraram uma queda significativa no número de LF circulantes, corroborando com diversos estudos que demonstram tal decréscimo em diferentes tipos de exercícios e intensidades, e em vários momentos, desde imediatamente após até 24 horas depois da sessão de exercício [6,24]. Contudo, essa diminuição de LF pós-exercício pode-se dever também à sua movimentação em direção de outros tecidos linfoides, onde permanecem a maior parte do tempo [24].

Mooren et al. [25] demonstraram que atletas e não atletas que correram uma maratona obtiveram maior aumento na apoptose dos LF, do que quando fizeram um exercício extenuante controlado em esteira. Esse dado indica que exercício de alta intensidade realizado em altas temperaturas pode levar à morte programada dos LF. Assim como em outros estudos citados, o presente estudo avaliou sujeitos treinados, visando a entender a resposta nesse tipo de indivíduos.

Este estudo apresenta como limitações a ausência do controle da ingestão de água durante a corrida, a ausência do controle da atividade autonômica e da medida da concentração sanguínea de catecolaminas, cortisol e citocinas e a não realização de uma corrida de $15 \mathrm{~km}$ em laboratório para comparação. Em conjunto, o conhecimento desses fatores poderia melhor fundamentar e fortalecer as discussões abordadas. 
Mesmo levando em conta estas limitações, pode-se concluir que a corrida de $15 \mathrm{~km}$ realizada em ambiente quente e seco induziu a uma típica resposta de leucocitose, modulada especialmente pelo aumento na contagem dos neutrófilos, acompanhada pela redução na contagem de linfócitos e eosinófilos, e sem alteração na contagem de monócitos/macrófagos e basófilos. Estes resultados ajudam a compreender melhor a leucocitose induzida pelo exercício e podem ser indicadores da intensidade do estresse promovido pelo exercício em condições ambientais extremas.

\section{NOTA}

Declaração de conflitos de interesse

Os autores declaram não haver conflitos de iteresse relevantes ao conteúdo deste estudo.

\section{REFERÊNCIAS}

1. Rhind SG, Gannon GA, Shek PN, Brenner IK, Severs Y, Zamecnik J, Buguet A, Natale VM, Shephard RJ, Radomski MW. Contribution of exertional hyperthermia to sympathoadrenal-mediated lymphocyte subset redistribution. J Appl Physiol (1985). 1999 Sept;87(3): $1178-85$.

2. Opdenakker G, Fibbe WE, Van Damme J. The molecular basis of leukocytosis. Immunol Today. 1998 Apr;19(4):182-9. http://dx.doi. org/10.1016/S0167-5699(97)01243-7

3. Pedersen BK, Hoffman-Goetz L. Exercise and the immune system: regulation, integration, and adaptation. Physiol Rev. 2000 July;80(3):1055-81.

4. Rhind SG, Shek PN, Shinkai S, Shephard RJ. Effects of moderate endurance exercise and training on in vitro lymphocyte proliferation, interleukin-2 (IL-2) production, and IL-2 receptor expression. Eur J Appl Physiol Occup Physiol. 1996;74(4):348-60. http://dx.doi org/10.1007/BF02226932

5. Abbas AK, Lichtman AH, Pillai S. Cellular and molecular immunology. 8th ed. Philadelphia: Elsevier Health Sciences; 2014.

6. Rhind SG, Gannon GA, Shek PN, Brenner IK, Severs Y, Zamecnik J, Buguet A, Natale VM, Shephard RJ, Radomski MW. Contribution of exertional hyperthermia to sympathoadrenal-mediated lymphocyte subset redistribution. J Appl Physiol (1985). 1999 Sept;87(3): $1178-85$.

7. McFarlin BK, Mitchell JB. Exercise in hot and cold environments: differential effects on leukocyte number and NK cell activity. Aviat Space Environ Med. 2003 Dec;74(12):1231-6.

8. Maisel A, Harris T, Rearden C, Michel M. Beta-adrenergic receptors in lymphocyte subsets after exercise. Alterations in normal individuals and patients with congestive heart failure. Circulation. 1990 Dec;82(6):2003-10. http://dx.doi.org/10.1161/01.CIR.82.6.2003

9. Brenner IK, Thomas S, Shephard RJ. Autonomic regulation of the circulation during exercise and heat exposure. Sports Med. 1998 Aug;26(2):85-99. http://dx.doi.org/10.2165/00007256-199826020-00003

10. Cheuvront SN, Kenefick RW, Montain SJ, Sawka MN. Mechanisms of aerobic performance impairment with heat stress and dehydration. J Appl Physiol (1985). 2010 Dec;109(6):1989-95.

11. Tatterson AJ, Hahn AG, Martin DT, Febbraio MA. Effects of heat stress on physiological responses and exercise performance in elite cyclists. J Sci Med Sport. 2000 June;3(2):186-93. http://dx.doi.org/10.1016/S1440-2440(00)80080-8

12. van Eeden SF1, Granton J, Hards JM, Moore B, Hogg JC. Expression of the cell adhesion molecules on leukocytes that demarginate during acute maximal exercise. J Appl Physiol (1985). 1999 Mar;86(3):970-6.

13. Lippi G, Salvagno GL, Solero GP, Franchini M, Guidi GC. Stability of blood cell counts, hematologic parameters and reticulocytes indexes on the Advia A120 hematologic analyzer. J Lab Clin Med. 2005 Dec;146(6):333-40. http://dx.doi.org/10.1016/j.lab. 2005.08 .004

14. Convertino VA, Armstrong LE, Coyle EF, Mack GW, Sawka MN, Senay LC Jr, Sherman WM. Acsm position stand: Exercise and fluid replacment. Med Sci Sports Exerc. 1996 Jan;28(1):i-vii. http://dx.doi.org/10.1097/00005768-199610000-00045

15. Maughan R, Shirreffs S. Exercise in the heat: challenges and opportunities. J Sports Sci. 2004 Oct;22(10):917-27. http://dx.doi. org/10.1080/02640410400005909

16. Suzuki K, Totsuka M, Nakaji S, Yamada M, Kudoh S, Liu Q, Sugawara K, Yamaya K, Sato K. Endurance exercise causes interaction among stress hormones, cytokines, neutrophil dynamics, and muscle damage. J Appl Physiol (1985). 1999 Oct;87(4):1360-7.

17. Wigernaes I, Høstmark AT, Strømme SB, Kierulf P, Birkeland K. Active recovery and post-exercise white blood cell count, free fatty acids, and hormones in endurance athletes. Eur J Appl Physiol. 2001 Apr;84(4):358-66. http://dx.doi.org/10.1007/s004210000365

18. Boxer LA, Allen JM, Baehner RL. Diminished polymorphonuclear leukocyte adherence: function dependent on release of cyclic AMP by endothelial cells after stimulation of $\beta$-receptors by epinephrine. J Clin Invest. 1980 Aug;66(2):268-74. http://dx.doi.org/10.1172/ JCI109853 
19. Jagels MA, Hugli TE. Mechanisms and mediators of neutrophilic leukocytosis. Immunopharmacology. 1994 July-Aug;28(1):1-18. http:// dx.doi.org/10.1016/0162-3109(94)90034-5

20. Iversen PO, Stokland A, Rolstad B, Benestad HB. Adrenaline-induced leucocytosis: recruitment of blood cells from rat spleen, bone marrow and lymphatics. Eur J Appl Physiol Occup Physiol. 1994;68(3):219-27. http://dx.doi.org/10.1007/BF00376770

21. Walsh NP, Whitham M. Exercising in environmental extremes. Sports Med. 2006;36(11):941-76. http://dx.doi.org/10.2165/00007256200636110-00003

22. Niess AM, Fehrenbach E, Lehmann R, Opavsky L, Jesse M, Northoff H, Dickhuth HH. Impact of elevated ambient temperatures on the acute immune response to intensive endurance exercise. Eur J Appl Physiol. 2003 May;89(3-4):344-51. http://dx.doi.org/10.1007/ s00421-003-0809-3

23. Pereira GB, Prestes J, Tibana RA, Shiguemoto GE, Navalta J, Perez SE. Acute resistance training affects cell surface markers for apoptosis and migration in CD4+ and CD8+ lymphocytes. Cell Immunol. 2012 Oct;279(2):134-9. http://dx.doi.org/10.1016/j.cellimm. 2012.11.002

24. Steensberg A, Morrow J, Toft AD, Bruunsgaard H, Pedersen BK. Prolonged exercise, lymphocyte apoptosis and F2-isoprostanes. Eur J Appl Physiol. 2002 May;87(1):38-42. http://dx.doi.org/10.1007/s00421-002-0584-6

25. Mooren FC, Lechtermann A, Völker K. Exercise-induced apoptosis of lymphocytes depends on training status. Med Sci Sports Exerc. 2004 Sept;36(9):1476-83. http://dx.doi.org/10.1249/01.MSS.0000139897.34521.E9 